ing the day, and the mercurial pill at night. Counter-irritation is especially useful. Open blisters, the tartar-emetic plaster, or even a caustic issue behind the trochanter. Dr. Hunt alludes to the hydriodate of potash as producing a powerful effect in some cases, but says he has not himself used it.

Sciatica, of which pain is the only symptom, returning in paroxysms like electric shocks, is nccnsionally met with, and sbould be treated like pure neuralgia, first by purgatives, and then by steel, quinine or arsenic with sedatives.

A case is given in which sciatica existed with piles and prolapsus ani, and the removal of the piles relieved the pain.

Persons subject to sciatica should wear Gannel drawers next to the skin, and if they are very susceptible to weather, washed-leather drawers over the fiannel, during the winter months. We have seen benefit in some cases of obstinate pain in the sciatic nerve from washed-leather drawers worn next to the skin.-British and Foreigu Med. Review.

\title{
ANTE-MORTEM EXAMINATION OF A CASE OF QUACKERY.
}

By John Dawson, M.D., of Jamestown, Ohio.

$\mathrm{T}_{\mathrm{HE}}$ abject of this report is to detail the symptoms, pathology and treatment of a case of quackery which lately fell into my hands, and for which, in consequence of some circumstances, 1 was compelled to prescribe.

Symptoms. -The case to which 1 have referred is a "botanical doctor," by the naine of Dr. L. T. He formerly resided in the East, says he there studied the "regular system," came to this country and was connected for a while with the "Botanic Faculty" at Worthington, in this State, as a professor. From considerations, best known to himself, he amputated limself from that learned body, and took up the occupation of "botanic doctor;" and has resided within the last three yeirs in as many different places, including Xenia, Dayton, and New Paris, all in this State. He is from appearance 35 or 40 years of age, tolerably tall, thin frame, and looks as though he enjoyed bald health. With this consideration the history of the case, we will proceed more directly to a our firstion of the symptoms as they were manifested on the occasion of our first and only interview. It may be proper, also, to state, that when our observations were made the patient was accouching hinself of a lectolerably the advantages of the "botanic systern." His language was cal know chaste, and rather mild. He spoke of the importance of medience as nowge to the people, of the imperfect condition of inedical scijudges; taught by the regular faculty, physicians themselves being the judges; of the "destructive consequences of using poisons," such as "regium, calomel, \&c., in the treatment of disease, and of the inability of "regular" physicians to treat diseases successfully, on account of bad with things rather no theories at all. He seemed to be really afficted hings of this kind; and supposed that homœopathy, patent pills, 
panaceas and nostrums of ever, kind were resorted to, because of inability in the regular faculty to answer the purposes for which it was instituted. Pained with such ballucinations as these, he labored also under a delusion that if the following "principles," as he called them, were made the basis of a system of medical practice, mankind would live to be taken out of the world with nothing, save and except old age.

1. Life is a state sustained by stimulants.

2. All disease is a diminution of vital action, therefore, disease is a unit.

3. Fever and inflammation are identical, and are both efforts of nature to throw off disease.

4. All remedial agents should act in harmony with the vital laws.

He exhibited traces of monomania on each of these "principles," and seemed to be abnormally confident that they were not only true, but that their adoption for the government of the "healing art "would redeem it from the darkness and confusion with which it is at present enshrouded, and place it upon a footing with the more brilliant and certain sciences of the day. With these syinptoms before me, the next thing was to ascertain the proper patholngy of the case. This, of course, could ouly be done by a just consideration of the history in connection with the symptoms, and such dissections, ante-mortem, as we are ordinarily permitted to make. Fron all these lights we inferred the pathology to consist: 1. In a morbid supposition that everything in this world. connected with human pursuits, is perfect, therefore the medical art should also be perfect; 2. In a congenital, or some other, lesion of the understanding, not knowing what the powers of the healing art really are, what the resources of medicine or the various morbid phases of disease are, and the control which an enlightened physician is able to exercise over the latter; 3 . In a very oblique conception of the nature of a poison, and its proper definition; 4 . In a deranged condition of the judgment-mistaking the theories of Rush, Brown and Sydenham for "principles" upon which to found the "botanical system ;" and lastly in an hypertrophied state of $\because$ acquisitiveness"-plagiarizing from these men in the regular profession, and not referring to them as being the authors of these theories.

Treatment.-Called upon by the patient himself for counsel and such treatment as I thought proper to institute, I yielded to the solicitation, and assumed the manarement of the case with the expectation of no other reward than a consciousness of having attended to a part of the duties of a physician. As is frequently the case in the treatment of disease, the indications to be fulfilled were various, and seemed to have grown out of several causes. Prominently standing out, as if demanding immediate relief, was the supposition that the medical art ought to be perfect, that physicians ought to be able to cure all diseases with which mankind are afflicted. For the relief of this symptom I prescribed an argument upon man's human nature, his liability to err, the circumscribed powers of his observation, the small annunt of actual knowledge that he possesses on any subject, and the folly, or rather foolishness, of expecting perfection on any subject at his hands. I endeavored to get it into him, that 
medical science, like all other sciences, was in its infancy, that it was now being cultivated with a great deal of success, and that in a short time it would take control of all disorders, except those which are the opprobrium medicorum, with which the Creator makes good his saying, that "It is appointed for man once to die."

For the disordered condition of his understanding, I ordered a careful, patient perusal of the elementary works on medical science, an attendance on the prelections of some of our teachers, with an examnination of their facilities for imparting useful and a vailable information on all medical subjects. On making known this prescription to my patient, he expressed himself as having previously tried the efficacy of such remedies, and found them to be incompetent to the cure of his malatly. I replied, that, unless he was insusceptible to the infuence of all remedial measures, he would certainly be cured; and that his former failure was perhaps relerable to the adoption of impure or inert means.

His optical illusions led him to believe, that poisons could exist in nothing but opium, calomel, and the preparations of antimony. To these, in connection with bloodletting, were due the poisonous consequences that follow the practice of the regular physicians. Knowing the defective character of the glasses through which be had been accustomed to look at poisons, we concluded to order them laid aside for a while, and have a pair provided through which be could see poison in all substances capable of acting in a noxious manner on the vital properties of the system. At first my patient expressed himself much pleased with this view; but as soon as he discovered that it embraced lobelia, cayenne, and number six, when inproperly administered, three favorites of his heart, his symptoms relapsed, and his vision became as much as ever distorted. The trouble under which he labored, in mistaking those old theories of Brown, Rush and Sydenham for principles, I regarded as one of the most serious symptoms with which he was afflicted. Its import seemed to point directly to a lesion of the judgment, which I was apprehensive night be congenital. Knowing, however, that a mild prescription could do no harm, but on the contrary, that it might serve to make the features of the disease inore obvious, I concluded to give one a trial. I administered to him : 1st. The fact, that the term principle, derived from the Latin principium, in its scientific acceptation is understood to mean a truth, either without proff, or considered as having been before proved; hence, when we use the term principle in medical science, we always have reference to an admitted truth, a something concerning which there theor no division of opinion; 2nd. That theory, derived from the Greek theoria, could, at most, mean nothing more than a speculative exposition of any subject, which theory or speculative exposition is only used or adopted, when, from the nature of the subject, it is incapable of being diversitrated, or of being made to assume the form of truth; hence, the dred subj theories on the modus operandi of medicines, and other kinanounts sucts, where the evidence of which we are in the possession, if thounts to nothing better than speculation or mere probability; 3d. That if the theories of Brown, Rush, Sydenham, \&c., had been susceptible 
of proof, their authors, those by whom they were originated, and who doubcless understood them the best, would never have left to any part of posterity, much less to "botanical doctors," a work, the value of which to their respective systerns, they so well understood; and, that if the genius of the authors of those theories could do nothing more than fascinate and anuse the medical world of their day, what can be expected at the hands of a class of men, whose only claim to distinction consists in an affected contempt of almost everything like medical knowledge, and a stupidity of intellect, that aims at notbing higher than the attainments of a drone? The effect of this prescription was most visible in an uneasiness of the general system, such as you would observe in an emaciated patient sitting upon a few sharp pegs. He was continually changing his attitude, resting a while upon one tuber of the ischia, then upon the other, until at last he exclaimed, that he would take no more of the prescription, until he returned home, to consult, I supposed, his friends. I prevailed on him, however, to stay a while longer, until I took him through the full course of prescriptions which was at first contemplated, promising him that his case, although almost beyond the reach, of hope, should not be neglected. at all, but that, on the contrary, the treatment should be continued more vigorously, if possible, so long as there was a trace of the vital principle that seemed to be worth preserving, or a fragnent of the disease capable in any way of interfering with the integrity of his system.

Partly, perbaps, by these assurances, and the anxiety of his friends to keep him from acting the "baby," he was induced to stay and see the end of the prescription.

The pathological state, for which I had yet to offer some measures of relief, consisted, as before remarked, in an hypertrophied or some, other bad state of that organ which phrenologists call "acquisitiveness," plagiarizing from the regular profession, the theories of some of the older physicians, without giving those physicians any credit at all for the invention of those theories, but, on the contrary, palming them off upon the ignorant and credulous as having been first brought forward by "botanic doctors." Difficult, as I was aware the correction of such a condition would prove itself to be, the idea of abandoning the case to nature for a spontaneous cure seemed to me to savor rather 100 much of the "expectant" mode of treating disease. The treatment was, therefore, continued by advising the patient: 1 . That the right to intellectual property, whether worth anything or not, is generally regarded as being more sacred than the right to any other kind of property, it is regarded as being as much more so as mind is superior to matter; 2. That all honorable men look upon plagiarism as a species of literary theft, for the commission of which no small degree of moral turpitude is required; 3. That all attempts by "botanic doctors" to use the theories of physicians of the regular faculty as their own, as having been first brought forward by them, will not fail to excite, in any one capable of appreciating literary labors, the most deliberate contempt. 4. That if the "botanic doctors" are unwilling to content thernselves with the sufficiency of the theories of their former head and centre, Dr. Samulal 
Thomson, viz., that "heat is life, and cold is death," it is their duty to corne out and acknowledge this to the world, and cease all attempts to keep life in their cause by plagiarizing from the older theorists of the regular profession. 5. That the "steam" and "pepper" humbugs, notwithstanding all the trickery of their advocates in assuming new names, such as "vegetable doctors," "botanic doctors," "reformed vegetable botanic doctors," \&c., are about to be recognized, by even the victims of the imposition, in their true character; and that in view of this fact, it would seem to behoove the fraternity to make preparations for returning to those avocations for the duties of which they are better qualifed, and from which they have so suddenly and unceremoniously taken their departures.

The effect of this prescription upon my patient was most evident in the confused appearance of his countenance, which seemed to indicate that he had been before unconscious of this peculiar feature of his disorder, not knowing that such plagiarisms would exclude him effectually from the society of the learned and honorable.

I know not whether the treatment of this case produced any permanent amendment in the syinptoms, for the patient became impaticnt and left without making a report. In good faith, however, it was conducted on my part, and the issue, as in other cases, time alone will make know't, either to the relief, or, perhaps, to the aggravation of his malady.

Remarks. - Without doubt it is a question of no small importance, and yet undecided, whether the public good would be more subserved by paying no attention at all to cases of this kind, or by meeting thein before the people and stripping them of those assumed pretensions by which the ignorant and credulnus are deceived. We know, that to notice and refute the sophistry of their rotten system incidentally, in.ports to them a degree of consequence, which, however small, is econonically used for the promotion of their cause; while to permit their boasting over the heads of physicians of having a superior system. and their traducing the practice of physicians, is calculated, if kept up without being refuted, to result in injurious consequences to both physician and patient. This being the case, we are of the opinion, that when they go spouting through the country on the merits of their system, as Was done in the case which I have reported, and by an individual, too, Who is to fill one of their professors' chairs this winter at Cincinnati, it is the best policy to meet them before the penple and expose them. We have made the experiment, and, not only found that it was easily accomplished, but that it was also successful. The sophistry of their matter is so very flimsy, that it requires but little effort to make the matter appear in all its naked deformity, to the judgment of any community, having an ordinary portion of common sense.-Western Lancet.

tubercuservations of Simon, Andral, \&ic., slow that in the early stage of r consumption, the blood corpuscles gradually diminish in num- 